\title{
Comparative Morphometric Variability of Meloidogyne graminicola Golden and Birchfield Infesting Rice (Oryza sativa L.) in West Bengal, India
}

\author{
Bipradeb Talukder*, Kusal Roy, P. Sudheer Kumar and Suvadip Saha \\ Department of Agricultural Entomology, BCKV, Mohanpur-741252, Nadia, W.B., India \\ *Corresponding author
}

\author{
A B S T R A C T
}

To study the intra-specific morphological and morphometric variations of Meloidogyne graminicola, rice roots having galls were collected from three different localities of southern part of West Bengal during 2014-2015. All the root gall inducing nematodes of

Keywords

Meloidogyne rice from Chakdah, Habra-II and Egra-II areas of West Bengal were identified as Meloidogyne graminicola Golden and Birchfield, 1965. All the populations or isolates of M. graminicola collected from rice growing areas of West Bengal revealed that second stage infective juveniles from Gayeshpur localities of Chakdah block of Nadia district exhibited high level of variability with regard to body length, tail length, tail terminus and 'a' value; while J2 from those of Ramkrishnapur (Egra-II of East Mindapore district) and Mena (Habra-II of North 24 Parganas district) areas had close morphometric similarity. Morphometric features of all the isolates of the second stage juveniles of M. graminicola associated with rice in West Bengal revealed close adherence with all the key diagnostic features of $M$. graminicola. There is an immense scope of further work with all the isolates of $M$. graminicola collected from rice growing areas of southern parts of West Bengal. Here, only morphological and morphometric variability of $M$. graminicola had been studied. Difference in biology, host nematode interaction, races (if any), biochemical and molecular differentiation among those isolates can be explored in future.

\section{Introduction}

Rice (Oryza sativa L.) is one of the most important food crops in the world, grown in diverse environments either as a sole crop (rainfed, irrigated or deep water) or as a major component in various cropping systems. India is second largest producer of rice in the world. Rice crop is affected by several abiotic and biotic stresses, of which plant parasitic nematodes constitute an important component. Cropping systems, involving different year specific crop sequences or fallow in a given area, create conditions of varying favorability for microbes, plant parasitic and free living nematodes and weeds, and thus affect the flora and fauna both qualitatively and quantitatively (Minton et al., 1986). The ecological conditions suitable for the cultivation of rice crop are very well congenial for the multiplication of nematodes infecting rice. About 300 nematode species belonging to 35 genera have been reported infesting rice (Upadhyay et al., 2014). A number of ecto and endo parasites of root, stem and foliar parts, e.g., Aphlenchoides besseyi, Ditylenchus angustus, Meloidogyne spp. Hirschmanniella spp. have been reported in the rice crop from the ricewheat cropping system, causing damage to 
the tune of $10.54 \%$ in rice alone (Jain et al., 2007). Among them, Meloidogyne graminicola, the root-knot nematode, has become a serious constraint in rice production due to rice cropping intensification and increasing scarcity of water (Prasad and Somasekhar, 2009). In India, outbreak of $M$. graminicola infestation in kharif rice has been witnessed in around 800 ha in Mandya district of Karnataka (Prasad et al., 2001) and many parts of India like West Bengal, Orissa, Assam, UP, Himachal Pradesh, etc.

In observance of growing concern of $M$. graminicola as a limiting factor of rice cultivation in the state, an effort has been made to study intra-specific morphological and morphometric variability or diversity of different populations of $M$. graminicola in southern part of West Bengal.

\section{Materials and Methods}

Root-Knot nematode infested rice root samples were collected from different areas of southern part of West Bengal, nematode population are extracted, killed, fixed, processed and permanent mounts were prepared for identification and observation on intra-specific morphological and morphometric variations of Meloidogyne graminicola Golden and Birchfield, 1965.

\section{Survey and collection of the nematode population}

Rice roots (approximately 50g) having galls were collected from three different localities viz., Gayeshpur of Chakdah block of Nadia district, Mena of Habra-II block of North 24Parganas district, and Ramkrishnapu of EgraII block of East Midnapore district in West Bengal during 2014-2015.

The samples were kept in a zip polythene bag, labelled and brought to the laboratory for extraction of nematodes and further processing to study the nematode specimens.

\section{Extraction of nematode population from soil and root sample}

Five grams of whitish galled roots washed gently under running tap water, roots were cut into $0.5 \mathrm{~cm}$ small pieces and split horizontally using sharp scissors and placed on double layer facial tissue paper resting on aluminum wire gauge and follow modified Baermann technique (Christie and Perry, 1951) for the recovery of second stage juveniles and adult males of $M$. graminicola.

The assembly was kept for 6 days. Every alternate day nematode suspension was collected from Petriplate and was filled up with fresh tap water. Nematode suspension was then kept in bottle, labelled and refrigerated for further process. The root samples were also stained adopting differential staining by $\mathrm{NaOCl}$ - acid fuchsin method (Byrd et al., 1983).

\section{Killing and fixing of nematode}

The nematode specimens containing adult males and second stage juveniles of $M$. graminicola were killed by hot-water-bath method. The concentrated nematode suspension was plunged into a beaker containing hot water at about $60-65^{\circ} \mathrm{C}$ and shaken the suspension continuously inside the beaker for about 2-3 minutes. Then the nematodes were killed and suspension of nematode was kept out of hot water to bring the suspension at room temperature as well as to allow the nematode for settling at the bottom of suspension. To concentrate the nematode suspension, excess amount of water was removed gently from the top of suspension using squeeze bottle without disturbing the whole. Killed nematodes were then fixed in FA 4:1 (40\% formaldehyde -10 
$\mathrm{ml}$, glacial acetic acid $-1 \mathrm{ml}$, distilled water $89 \mathrm{ml}$ ) and kept separately in the labelled vial for further study.

Processing of second stage juveniles and adult males of $M$. graminicola for permanent mount

For morphological and morphometric studies the fixed nematode specimens from each population were processed by glycerolethanol method (Seinhorst, 1959).

Mounting of second stage juveniles and adult males of $M$. graminicola

The processed specimens were permanently mounted in pure anhydrous glycerol. A small drop of glycerol was placed on the centre of clean glass slide measuring 3" x1". About 7-8 specimens of processed nematodes were picked up and placed in the centre of glycerol drop so that their head pointing at same direction, making sure that they were resting on the surface of glass slide and not floating on the surface of the drop. Microscopic cover glass of $18 \mathrm{~mm}$ diameter and $0.17 \mathrm{~mm}$ thickness was placed over the specimen and sealed by the paraffin wax-ring method (de Maeseneer and d' Herde, 1963).

\section{Methods of preparation of perineal patterns of females of Meloidogyne}

The cuticular patterns around vulva and anus (perineal pattern) are characteristics for identification of the species of Meloidogyne. Therefore, preparation of good patterns from mature female specimens is essential for preliminary identification of the Meloidogyne sp. To prepare perineal pattern, stained adult females of root knot nematodes were dissected out from galled rice roots using fine needles and forceps in a drop of glycerine on perplex slide. The female specimen was cut into two halves with a sharp cataract (optical) knife under stereoscopic binocular microscope (Carl Zeiss-Stemi, 2000c). The posterior half of female's body was selected and placed into a drop of $45 \%$ lactic acid on slide, pressed gently to remove the body tissues adhered to the perineal areas leaving vulval tissues undisturbed. Then the transparent cuticle of posterior end was trimmed to a square pattern so that only the perineal area (area around vulva and anus) remains in a piece of cuticle that is 5-10 times the perineal region. The perineal pattern was then cleaned with due care by fine nylon bristle to remove debris. The perineal patterns were then transferred to a drop of anhydrous glycerin on a clean glass slide. All the patterns were arranged in a straight line and set the patterns in such a way that inner surface of the cuticle must touch the surface of the glass slide. The patterns were gently pressed against the glass slide to avoid floating on glycerin. After arranging patterns, three glass-wool pieces of equal width were placed radially in a glycerin drop at $120^{\circ}$ angle, place cover-slip gently over the specimen and sealed by paraffin wax-ring method (de Maeseneer and d' Herde, 1963).

\section{Preparation of temporary mount of mature females}

Stained adult females and eggs of $M$. graminicola were teased out from galled rice roots using fine needles and forceps and taken in a drop of glycerine on glass slide using Camel's hair brush (00 size). A cover slip was placed over it and sealed with transparent nail polish and observed under stereoscopic trinocular microscope (Nikon $\mathrm{CiS}$ ) to record key morphological and morphometric features.

Keys for identification of Meloidogyne graminicola

The identification key of Meloidogyne graminicola based on perineal pattern of female was given by Eisenback et al., (1980); 
Key based on morphology of head and stylet of males was given by Eisenback and Triantaphyllou (1991. Key based on stylet of female and distance of the excretory pore to the head end was given by Eisenback et al., (1980). These keys were used in the present study for the study all the isolates.

Observation on morphological and morphometric variations of Meloidogyne graminicola

Three populations of the mentioned nematode species of rice were examined for morphometric characterization for the generation of information on intra-specific variations. The following set of parameters used to characterize nematode species were developed initially by de Man in 1876 and 1880 and added to, modified and amended by Cobb (1914), Thorne (1949) and others. These are often called as the de Man Formula or the de Man Indices.

$\mathrm{L}=$ total body length

Tail $=$ portion of body from anus or cloaca to posterior terminus

\section{Ratios}

$\mathrm{a}=$ body length /greatest body width

$\mathrm{b}=$ body length/length of oesophagus

$b^{\prime}=$ body length/distance from anterior end to

basal oesophageal gland bulb

$\mathrm{c}=$ body length $/$ tail length

$c^{\prime}=$ tail length/ anal body width (abw)

Morphometric parameters of second stage juveniles and adult males of $M$. graminicola (All measurements are in $\mu \mathrm{m}$ )

$\mathrm{L}=$ Total body length i.e., head to tail end
Greatest body width

Stylet length

Length of anterior (conical) parts of spear (conus)

Length of shaft of spear

Stylet knob width

Inclination of stylet knob

Position of hemizonid (anterior or posterior to

excretory pore)

Excretory pore from anterior end

Oesophagus length (up to basal bulb)

DEGO from stylet base

Number of lateral lines

Distance of anus from anterior end

Spicule length

Gubernaculum length

Head region (continuous/offset/sunken)

Head height

Head annules

Anal body width

Tail shape and length

Hyaline area of tail

\section{Morphometric parameters of perineal patterns}

LVS= Length of vulval slit $(\mu \mathrm{m})$

$\mathrm{AVS}=$ Distance from anus to vulval slit $(\mu \mathrm{m})$

$\mathrm{VSTT}=$ Distance from vulval slit to tail terminus $(\mu \mathrm{m})$

$\mathrm{ATT}=$ Distance from anus to tail terminus $(\mu \mathrm{m})$

$\mathrm{IPD}=$ Interphasmidal distance $(\mu \mathrm{m})$ 
PVS= Phasmid-vulval slit $(\mu \mathrm{m})$

$\mathrm{PA}=$ Phasmid-anus $(\mu \mathrm{m})$

\section{Morphometric parameters of adult females}

Median body length $(\mu \mathrm{m})$

Median body width $(\mu \mathrm{m})$

Sylet length $(\mu \mathrm{m})$

\section{$\operatorname{DEGO}(\mu \mathrm{m})$}

Distance from head to excretory pore $(\mu \mathrm{m})$

Angle of neck inclination from longitudinal body axis $\left({ }^{\circ}\right)$

Shapes of stylet cone, shaft and knob

Position of excretory pore

The measurement of all the specimens was taken under trinocular compound microscope (Nikon CiS) taking the support of image capturing device Nikon DS- Ri2 and image analyzing device NIS-Elements BR 4.30.00.

\section{Statistical analysis}

To compare morphometric data of three different population Meloidogyne graminicola arithmetic mean, standard deviation (SD), and co-efficient of variation (CV) were computed. Considering $\mathrm{CV}$ values the taxonomic characters were rated as least variable, moderately variable and highly variable, using scale $<12 \%, 12-20 \%$ and $>20 \%$ for female, $<8 \%, 8-12 \%$ and $>12 \%$ for second stage juveniles (J2) respectively. The data thus obtained was compared with the earlier descriptions of this species (Golden and Birchfield, 1965; Hunt and Handoo, 2009).

\section{Results and Discussion}

All the root gall inducing nematodes of rice from Chakdah, Habra-II and Egra-II areas of West Bengal were identified as Meloidogyne graminicola Golden and Birchfield, 1965. All the comparable morphometric observations are found similar to the findings of Golden and Birchfield, 1965 and Triantaphyllou, 1991.

Populations of M. graminicola procured from three different rice growing localities were designated as Chakdah isolate, Habra-II isolate and Egra-II isolate.

\section{Comparative morphological and morphometric variability of different isolates of $M$. graminicola females associated with rice}

Comparative morphometric data of 3 isolates of M. graminicola female are tabulated in table 1. In all the three isolates of Chakdah, Habra-II, Egra-II, Adult females are round to pear shaped, looks like typically graminis type, body somewhat elongate with distinct terminal protuberance. Stylet cone slightly curved dorsally or straight. Stylet shaft cylindrical to slightly wider and stylet knobs set off, transversally elongate. Oesophagous has a large muscular bulb having conspicuous valve plates. Excretory Pore posterior to spear base.

\section{Chakdah isolate}

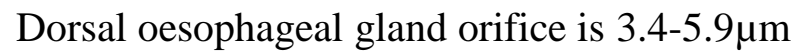
anterior from spear base. Considering ' $\mathrm{CV}$ ' values median body length and stylet length were found as least variable characters while median body width, DEGO and distance of excretory pore from anterior end were rated as moderately variable characters. In adult female, angle of neck inclination from longitudinal body axis varied from 0 to $75.6^{\circ}$. 
Here, it has been observed as highly variable character and hence it is of least diagnostic value.

\section{Habra-II isolate}

Dorsal oesophageal gland orifice is $3.0-5.2 \mu \mathrm{m}$ anterior from spear base. Considering ' $\mathrm{CV}$ ' values stylet length and distance of excretory pore from anterior end were found as least variable characters while median body length, median body width, DEGO and were rated as moderately variable characters.

In adult female, angle of neck inclination from longitudinal body axis varied from 0 to $62.4^{\circ}$, which is highly variable character and is of least taxonomic value.

\section{Egra-II isolate}

Dorsal oesophageal gland orifice is $3.2-5.6 \mu \mathrm{m}$ anterior from spear base. Considering ' $\mathrm{CV}$ ' values distance of excretory pore from anterior end was found most stable character for this isolate while median body length, median body width, stylet length and DEGO were rated as moderately variable characters. In comparison to other two isolates, here variation in neck inclination was found low.

\section{Comparative Morphological and morphometric variability of perineal patterns of different isolates of $M$. graminicola female associated with rice}

Comparative variability of perineal patterns of 3 isolates of $M$. graminicola female associated with rice in West Bengal was tabulated in table 2. In all the three isolates of Chakdah, Habra-I, Egra the Perineal patterns of $M$. graminicola female were either rounded or oval in shape. Lateral field was absent and not clearly defined. Striae smooth, short and continuous but sometimes wavy. Punctation in tail terminal area was absent.

Table.1 Comparative morphometric data of 3 isolates of $M$. graminicola female

\begin{tabular}{|c|c|c|c|c|}
\hline \multirow{3}{*}{ Taxonomic characters } & \multicolumn{3}{|l|}{ Present findings } & \multirow{2}{*}{$\begin{array}{l}\text { After Golden and } \\
\text { Birchfield, 1965; } \\
\text { Eisenback et al., } \\
\text { 1980; Eisenback } \\
\text { and } \\
\text { Triantaphyllou, } \\
1991\end{array}$} \\
\hline & Chakdah & Habra-II & Egra-II & \\
\hline & Mean (Range) & Mean (Range) & Mean (Range) & Mean (Range) \\
\hline Median body length $(\mu \mathrm{m})$ & $\begin{array}{l}545.4 \\
(399.2-616.4)\end{array}$ & $\begin{array}{l}567.9 \\
(350.0-672.3)\end{array}$ & $\begin{array}{l}566.9 \\
(434.8-745.5)\end{array}$ & $\begin{array}{l}573 \\
(445-765)\end{array}$ \\
\hline Median body width $(\mu \mathrm{m})$ & $\begin{array}{l}363.8 \\
(210.7-452.3)\end{array}$ & $\begin{array}{l}385.5 \\
(274.0-464.9)\end{array}$ & $\begin{array}{l}348.7 \\
(210.3-457.8)\end{array}$ & $\begin{array}{l}419 \\
(275-520)\end{array}$ \\
\hline Stylet length $(\mu \mathrm{m})$ & $12.5(12.0-13.3)$ & $11.2(9.4-11.9)$ & $12.7(9.9-16.1)$ & $\begin{array}{l}11.08(10.6-11.2) / \\
10.5-11.0\end{array}$ \\
\hline DEGO $(\mu \mathrm{m})$ & $4.7(3.4-5.9)$ & $3.9(3.0-5.2)$ & $4.1(3.2-5.6)$ & $3-4$ \\
\hline
\end{tabular}


Table. 2 Comparative variability of perineal patterns of 3 isolates of M. graminicola female associated with rice in West Bengal

\begin{tabular}{lccc}
\hline Taxonomic characters & $\begin{array}{c}\text { Chakdah } \\
\text { Mean (Range) }\end{array}$ & $\begin{array}{c}\text { Habra-II } \\
\text { Mean (Range) }\end{array}$ & $\begin{array}{c}\text { Egra-II } \\
\text { Mean (Range) }\end{array}$ \\
\hline LVS $(\mu \mathrm{m})$ & $21.2(16.9-27.7)$ & $24.1(18.7-29.8)$ & $23.3(18.7-34.8)$ \\
AVS $(\mu \mathrm{m})$ & $12.8(8.2-15.7)$ & $12.9(8.6-17.4)$ & $11.6(7.6-18.0)$ \\
VSTT $(\mu \mathrm{m})$ & $16.4(14.1-20.0)$ & $15.8(10.6-20.3)$ & $15.0(11.4-20.6)$ \\
ATT $(\mu \mathrm{m})$ & $3.6(2.5-5.9)$ & $2.9(1.6-6.2)$ & $3.4(2.1-5.6)$ \\
IPD $(\mu \mathrm{m})$ & $14.4(6.7-21.2)$ & $11.0(7.5-15.8)$ & $12.5(7.3-18.7)$ \\
PVS $(\mu \mathrm{m})$ & $23.0(19.0-29.6)$ & $21.5(16.8-25.5)$ & $20.4(15.1-29.3)$ \\
PA $(\mu \mathrm{m})$ & $9.5(6.9-16.8)$ & $8.0(4.5-11.8)$ & $9.2(7.2-12.3)$ \\
\hline
\end{tabular}

Table. 3 Comparative morphometric data of $\mathrm{J} 2$ of 3 isolates of $M$. graminicola

\begin{tabular}{|c|c|c|c|c|}
\hline \multirow{3}{*}{$\begin{array}{l}\text { Taxonomic } \\
\text { characters }\end{array}$} & \multicolumn{3}{|c|}{ Present findings } & \multirow{2}{*}{$\begin{array}{c}\text { After Golden and } \\
\text { Birchfield, 1965; } \\
\text { Eisenback et al., } \\
1980\end{array}$} \\
\hline & Chakdah & Habra-II & Egra-II & \\
\hline & Mean (Range) & Mean (Range) & Mean (Range) & Mean (Range) \\
\hline Head cap & $\begin{array}{c}\text { Anteriorly } \\
\text { flattened, elongate }\end{array}$ & $\begin{array}{c}\text { Anteriorly flattened, } \\
\text { elongate }\end{array}$ & $\begin{array}{c}\text { Anteriorly flattened, } \\
\text { elongate }\end{array}$ & $\begin{array}{c}\text { Anteriorly } \\
\text { flattened, elongate }\end{array}$ \\
\hline Head region & $\begin{array}{l}\text { Rounded, usually } \\
\text { smooth }\end{array}$ & $\begin{array}{l}\text { Rounded, usually } \\
\text { smooth }\end{array}$ & $\begin{array}{l}\text { Rounded, usually } \\
\text { smooth }\end{array}$ & $\begin{array}{l}\text { Rounded, usually } \\
\text { smooth }\end{array}$ \\
\hline Stylet width & $\begin{array}{c}\text { Narrow cone and } \\
\text { shaft }\end{array}$ & $\begin{array}{c}\text { Narrow cone and } \\
\text { shaft }\end{array}$ & $\begin{array}{c}\text { Narrow cone and } \\
\text { shaft }\end{array}$ & $\begin{array}{c}\text { Narrow cone and } \\
\text { shaft }\end{array}$ \\
\hline Stylet knob & $\begin{array}{l}\text { Set off, small and } \\
\text { round }\end{array}$ & $\begin{array}{l}\text { Set off, small and } \\
\text { round }\end{array}$ & $\begin{array}{l}\text { Set off, small and } \\
\text { round }\end{array}$ & $\begin{array}{c}\text { Set off, small and } \\
\text { round }\end{array}$ \\
\hline $\begin{array}{l}\text { Stylet length } \\
(\mu \mathrm{m})\end{array}$ & $10.7(9.2-11.7)$ & $11(9.6-13.4)$ & $10.9(10.1-12.8)$ & $11-12$ \\
\hline DEGO $(\mu \mathrm{m})$ & $3.7 \pm 0.6(2.6-4.5)$ & $3.4(3-4)$ & $3.8(3.3-4.0)$ & $2.8-3.4$ \\
\hline $\begin{array}{l}\text { Tail length } \\
(\mu \mathrm{m})\end{array}$ & $69.2(50.0-82.2)$ & $64.0(55.9-67.3)$ & $63.2(56.0-66.5)$ & $67-76$ \\
\hline Terminus $(\mu \mathrm{m})$ & $22.0(15.6-27.4)$ & $18.2(15.9-20.2)$ & $17.8(15.1-20.7)$ & $14-21$ \\
\hline Body length $(\mu \mathrm{m})$ & $\begin{array}{c}468.4 \\
(395.0-575.6)\end{array}$ & $\begin{array}{c}432.6 \\
(420.6-453.7)\end{array}$ & $\begin{array}{c}431.4 \\
(412.2-443.9)\end{array}$ & $\begin{array}{c}441 \\
(415-484)\end{array}$ \\
\hline $\mathrm{a}$ & $31.6(22.5-41.5)$ & $29.9(25.9-34.8)$ & $27.5(22.8-30.3)$ & $24.8(22.3-27.3)$ \\
\hline $\mathrm{b}$ & $2.8(2.2-4.2)$ & $2.9(2.2-3.6)$ & $2.5(2.0-3.8)$ & $3.2(2.9-4.0)$ \\
\hline $\mathrm{c}$ & $6.9(4.9-8.7)$ & $6.8(6.4-7.6)$ & $6.8(6.2-7.7)$ & $6.2(5.5-6.7)$ \\
\hline
\end{tabular}


Fig.1 a- M. graminicola female (4x), b- perineal pattern (100x), c- head region of female (100x), d- J2 (20x) and e- head region of J2 (20x). (Gayeshpur, Chakdah, Nadia. West Bengal)

a.

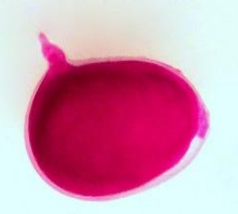

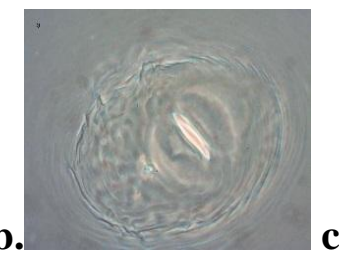
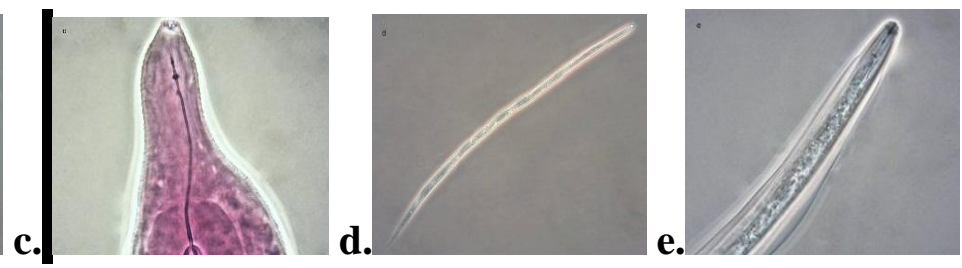

Fig.2 a-M. graminicola female (10x), b- perineal pattern (100x), c-head region of female (40x), d- J2 (20x)and e- head region of J2 (100x)(Mena, Habra-II, North 24 Parganas, West Bengal)
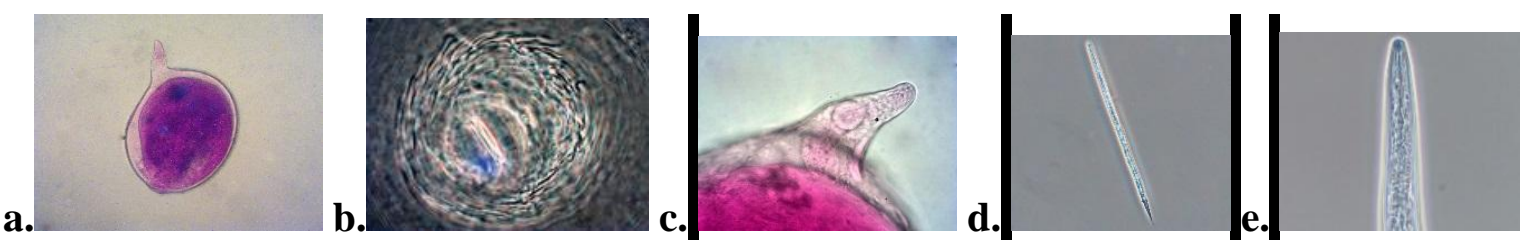

Fig.3 a- M. graminicola female (10x), b- perineal pattern (100x), head region of female (40x), J2 (20x) and head region of J2 (100x). (Ramkrishnapur, Egra-II, East Midnapore, West Bengal)

a.

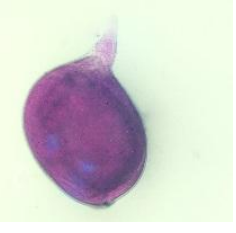

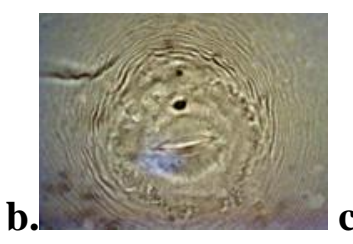

c.

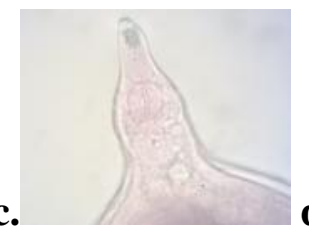

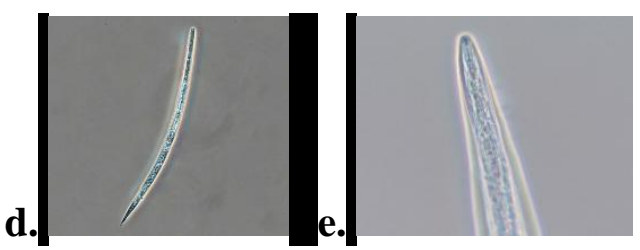

\section{Chakdah isolate}

Length of vulval slit was $16.9-27.7 \mu \mathrm{m}$, distance from vulval slit to anus and vulval slit to tail terminus were $8.2-15.7 \mu \mathrm{m}$ and $14.1-20.0 \mu \mathrm{m}$, respectively. All these features were found moderately variable considering their CV values.. Inter-phasmidal distance was $6.7-21.2 \mu \mathrm{m}$.

\section{Habra-II isolate}

Length of vulval slit was $18.7-29.8 \mu \mathrm{m}$, distance from vulval slit to anus, vulval slit to tail terminus and vulval slit to phasmid were 8.6-17.4 $\mu \mathrm{m}, 10.6-20.3 \mu \mathrm{m}$ and $16.8-25.5 \mu \mathrm{m}$, respectively. All these features were found moderately variable considering their $\mathrm{CV}$ values. Inter-phasmidal distance was 7.5$15.8 \mu \mathrm{m}$.

\section{Egra-II isolate}

Length of vulval slit was $18.7-34.8 \mu \mathrm{m}$, distance from vulval slit to anus, vulval slit to tail terminus and vulval slit to phasmid were 7.6-18.0 $\mu \mathrm{m}, 11.4-20.6 \mu \mathrm{m}$ and $15.1-29.3 \mu \mathrm{m}$, respectively. Taxonomic features viz., LVS, VSTT, PVS and PA were found moderately variable considering their $\mathrm{CV}$ values. AVS for this particular isolate was found highly variable Inter-phasmidal distance was 7.3$18.7 \mu \mathrm{m}$.

Comparative variability of $\mathbf{J} 2$ of $M$. graminicola associated with rice in West Bengal

All the population or isolates of $M$. graminicola collected from rice growing areas of West Bengal revealed that second stage 
infective juveniles from Gayeshpur localities of Chakdah block of Nadia district exhibited high level of variability with regard to body length, tail length, tail terminus and 'a' value; while $\mathbf{J} 2$ from those of Ramkrishnapur (EgraII of East Mindapore district) and Mena (Habra-II of North 24 Parganas district) areas had close morphometric similarity.

Morphometric features of all the isolates of the second stage juveniles of $M$. graminicola associated with rice in West Bengal as shown in table 3 revealed close adherence with all the key diagnostic features of $M$. graminicola has laid down by Golden and Birchfield, 1965; Eisenback et al., 1980; Eisenback and Triantaphyllou, 1991

It can be concluded that all the root gall inducing nematodes of rice from Chakdah, Habra-II and Egra-II areas of West Bengal were identified as Meloidogyne graminicola Golden and Birchfield, 1965. All the population or isolates of $M$. graminicola collected from rice growing areas of West Bengal revealed that second stage infective juveniles from Gayeshpur localities of Chakdah block of Nadia district exhibited high level of variability with regard to body length, tail length, tail terminus and 'a' value; while $\mathrm{J} 2$ from those of Ramkrishnapur (EgraII of East Mindapore district) and Mena (Habra-II of North 24 Parganas district) areas had close morphometric similarity. Morphometric features of all the isolates of the second stage juveniles of $M$. graminicola associated with rice in West Bengal revealed close adherence with all the key diagnostic features of M. graminicola.

\section{References}

Byrd, D.W., Jr., Kirkpatrick, T. and Barker, K.R. 1983. An improved technique for clearing and staining plant tissue for detection of nematodes. J. Nematol.,
14:142-43.

Christie, J.R. and Perry, V.G. 1951. Removing nematode from soil. Proc. Helminth. Soc. Washington, 18: 106108.

De Maeseneer, J. and D'Herde, C.J. 1963. Méthodes utilisées pour l'étude anguillules libres $\mathrm{du}$ sol. Revue Agriculture, Bruxelles, 16: 441-47.

Eisenback, J. D., Hirschmann, H., Sasser, J. N. and Triantaphyllou, A. C. 1981. A guide to the four most common species of root-knot nematodes (Meloidogyne spp.), with a pictorial key. A Cooperative Publication of The Departments of Plant Pathology and Genetics North Carolina State University and The United States Agency for International Development Raleigh, North Carolina, May, 1981, pp. 48.

Eisenback, J.D. and Triantaphyllou, H.H. 1991. Root Knot Nematode: Meloidogyne Species and Races. In. Manual of Agricultural Nematology (Ed. Nickle, W.R). 191-274.

Eisenback, J.D., Hirschmann, H. and Triantaphyllou, A.C. 1980. Morphological comparison of Meloidogyne female head structures, perineal patterns and stylets. $J$. Nematol., 12: 300-313.

Golden, A.M. and Birchfield, W. 1965. Meloidogyne graminicola (Heteroderidae) a new species of rootknot nematode from grass. Proceedings of the Helminthology Society of Washington, 32:228-231.

Hunt, D.J. and Handoo, J.A. 2009. Taxonomy, Identification and Principal Species. In. Root-knot Nematodes (Eds. Perry, R.N., Moens, M. and Starr, J.L.), CABI, Wallingford, Oxfordshire, UK, pp. 55-97.

Jain, R.K., Mathur, K.N. and Singh, R.V. 2007. Estimation of losses due to plant 
parasitic nematodes on different crops in India. Indian J. Nematol. 37:217219.

Minton, N.A. 1986. Impact of conservation tillage on nematode population, $J$. Nematol., 18: 135-140.

Prasad, J.S. and Somasekhar, N. 2009. Nematode pest of rice: diagnosis and management.Technical bulletin no. 38, Director of Rice Research (ICAR), Hyderabad, pp. 29.

Prasad, J.S. and Varaprasad, K.S. 2001. Ufra nematode, Ditylenchus angustus is seed borne. Crop Protection, 21(1): 75-76.

Seinhorst, J.W. 1959. A rapid method for the transfer of nematodes from fixative to anhydrous glycerine. Nematologica, 8: 67-69.

Upadhyay, V., Bhardwaj, N. R., Neelam and Sajeesh, P.K. 2014. Meloidogyne graminicola (Golden and Birchfield): Threat to Rice Production. Research Journal of Agriculture and Forestry Sciences, 2(3): 31-36.

\section{How to cite this article:}

Bipradeb Talukder, Kusal Roy, P. Sudheer Kumar and Suvadip Saha. 2017. Comparative Morphometric Variability of Meloidogyne graminicola Golden and Birchfield Infesting Rice (Oryza sativa L.) in West Bengal, India. Int.J.Curr.Microbiol.App.Sci. 6(7): 2422-2431. doi: https://doi.org/10.20546/ijcmas.2017.607.344 